\section{AB0025 STUDY OF LYMPHOCYTE PHENOTYPE IN RHEUMATOID ARTHRITIS PATIENTS}

IR Kolosova, ER Polosukhina, AY Baryshnikov, GV Loukina, YA Sigidin. Department of Clinical Pharmacology, Institute of Rheumatology, Moscow, Russia

10.1136/annrheumdis-2001.930

\section{Background}

Objectives To examine the expression of surface markers on lymphocytes in patients with rheumatoid arthritis (RA).

Methods Peripheral blood samples were obtained from 36 patients with active RA (mean disease duration 8,8 years, mean age 54,8 years) and 18 normal subjects. The patients were treated with NSAIDs, DMARDs and prednisolone. Fluorescent flow cytometry on FACScan (Becfon Dichinson) was used to assess the expression of CD3, CD4, CD5, CD7, CD8, CD11b, CD16, CD18, CD20, CD25, CD26, CD50, CD54, CD56, CD71, CD95, HLA-DR antigens.

Results The expression of CD16 antigen on peripheral blood lymphocytes was elevated as compared with healthy volunteers $(16,5 \pm 1,7 \%$ vs $11 \pm 1,5 \%, \mathrm{P}=0,03)$.

The percentage of lymphocytes expressing CD95 antigen was higher in patients treated with NSAIDs $(\mathrm{n}=24)$ as compared with controls $(32,9 \pm 3,6 \%$ vs $25,6 \pm 2,9 \%, \mathrm{P}=0,05)$. The expression of CD 95 antigen correlated with expression of antigens ND26 ( $r=0,77)$, CD71 and CD25 ( $r=0,6)$.

Conclusion Lymphocyte phenotype in RA patients is characterised by the increased expression of CD16.

\section{AB0026 LIMPHOCYTIS EXPRESSION OF P-GLYCOPROTEIN ON PERIPHERAL BLOOD IN RHEUMATOID ARTHRITIS PATIENTS}

IR Kolosova, ER Polosukhina, AY Baryshnikov, GV Loukina, YA Sigidin. Department of Clinical Pharmacology, Institute of Rheumatology, Moscow, Russia

10.1136/annrheumdis-2001.931

\section{Background}

Objectives To examine the expression of the multidrug resistance P-glycoprotein (P-gp 170) in patients with rheumatoid arthritis (RA). P-gp 170 is a pump molecule which decreases intracellular drug concentrations by increasing drug efflux from cells.

Methods Peripheral blood samples were obtained from 10 patients with active RA, and 8 normal subjects. The patients were treated with NSAIDs. Previous therapy with DMARDs was ineffective in 7 patients. 3 patients were not treated with DMARDs. Fluorescent flow cytometry on FACScan (Becfon Dichinson) was used to assess the expression of P-gp 170, with monoclonal antibodies (UIC2 PE, Immunotech).

Results The expression of P-gp on peripheral blood lymphocytes was elevated compared with control $(29,6 \pm 9,4 \%$ vs $1,6 \pm$ $0,4 \%, P=0,03)$. We did not observe any association between glycoprotein $\mathrm{P}$ expression and age, sex, disease activity, duration and stage of RA. The expression of P-gp 170 correlated with expression of antigens CD8 $(r=0,85)$ and CD71 $(r=0,83)$.

Conclusion The patient with RA showed increased expression of P-gp 170 as compared to the control. Further studies are needed to evaluate the potential implication of P-gp in drug resistance in RA.

\section{AB0027 TNF-ALFA RESPONSES INDUCED BY DIFFERENT ENTEROBACTERIA AND GRAM-POSITIVE CELL WALLS OF NORMAL INTESTINAL MICROBIOTA IN EARLY RHEUMATOID ARTHRITIS}

${ }^{1}$ RK Luukkainen, ${ }^{2} \mathrm{~T}$ Cheng, ${ }^{2} \mathrm{M}$ Rimpiläinen, ${ }^{3} \mathrm{~T}$ Möttönen, ${ }^{4} \mathrm{U}$ Yli-Kerttula, ${ }^{3} \mathrm{R}$ Saario, ${ }^{2} \mathrm{P}$ Toivanen. ${ }^{1}$ Department of Rheumatology, Satalinna Hospital, Harjavalta; ${ }^{2}$ Department of Medical Microbiology; ${ }^{3}$ Department of Medicine, University of Turku, Turku; ${ }^{4}$ Department of Medicine, University of Tampere, Tampere, Finland

\subsection{6/annrheumdis-2001.932}

Background The aetiology of the rheumatoid arthritis (RA) is unknown. A variety of infective agents have been proposed to be the etiological factor of the disease.

Objectives To study whether enterobacteria and Gram-positive bacterial cell walls (BCW) derived from normal intestinal microbiata are involved in the etiopathogenesis of early rheumatoid arthritis.

Methods Peripheral blood mononuclear cells (PBMC) and synovial fluid mononuclear cells (SFMC) were isolated from patients with early RA (the average duration of 3 months). The tumour necrosis factor-alpha (TNF-alfa) responses to heat-killed Salmonella enteritidis, Yersinia enterocolitica and Escherichia coli, and to Gram-positive BCW derived from four common intestinal indigenous bacteria, Eubacterium aerofaciens, Eubacterium limosum, Lactobacillus casei and Lactobacillus fermentum, and a BCW derived from a pathogen, Streptococcus pyogenes were investigated.

Results The results obtained indicate that these bacterial antigens induce TNF-alfa responses of PBMC and SFMC from at least some patients with early RA. However, the responses are not spesific for any particular bacterial antigen tested. The responses observed are similar to those observed in the patients with other inflammatory arthritides.

Conclusion These results suggest that SFMC reacting with BCW exist in some patients with early RA. They are in agreement with the hypothesis that $\mathrm{BCW}$ derived from normal intestinal microbiota might be involved in the etiopathogenesis of chronic arthritides, including RA.

\section{AB0028 THE SERUM LEVELS OF SOLUBLE ICAM-1, NITRIC OXIDE AND XANTHINE OXIDASE IN RHEUMATOID ARTHRITIS}

A Erdal, K Senel, S Taysi. Physical Therapy and Rehabilitation, Atatürk University Medical Faculty, Erzurum, Turkey

10.1136/annrheumdis-2001.933

\section{Background}

Objectives This study was carried out to determine the serum levels of soluble intercellular adhesion molecule 1 (ICAM-1), nitric oxide and xanthine oxidase in patients with rheumatoid arthritis (RA) and to investigate the correlations between sICAM-1 and nitric oxide and xanthine oxidase.

Methods Serum samples were obtained from 30 patients with active RA and 20 healthy control subjects. sICAM-1, nitric oxide and xanthine oxidase levels were determined.

Results sICAM-1, nitric oxide and xanthine oxidase levels were significantly elevated in patients with RA $(\mathrm{p}<0.001)$. We found a significant positive correlation between $\mathrm{s}$ ICAM-1 and nitric oxide $(\mathrm{r}=0.426, \mathrm{p}<0.05)$. There was also a significant positive correlation between $\mathrm{s}$ ICAM-1 and xanthine oxidase $(\mathrm{r}=$ $518, \mathrm{p}<0.01)$. 